\title{
The Influence of Abnormal Data on Relay Protection
}

\author{
Xuze Zhang1, Xiaoning Kang1, Yali Ma², Hao Wang1, Qiyue Huang1 \\ ${ }^{1}$ Shaanxi Key Laboratory of Smart Grid (Xi'an Jiaotong University), Xi'an Jiaotong University, Xi'an, China \\ ${ }^{2}$ Tianjin Power Transmission and Transformation Engineering Company, Tianjin, China \\ Email: dianqieefourier@163.com
}

How to cite this paper: Zhang, X.Z., Kang, X.N., Ma, Y.L., Wang, H. and Huang, Q.Y. (2017) The Influence of Abnormal Data on Relay Protection. Energy and Power Engineering, 9, 95-101. https://doi.org/10.4236/epe.2017.94B012

Received: January 16, 2017

Accepted: March 30, 2017

Published: April 6, 2017

\begin{abstract}
The parameters of abnormal data are defined and their influence on the original data and Fourier Algorithm is studied. A formula is proposed to quantify how the abnormal data influences the amplitude calculated by Fourier Algorithm. Two simulation models are established in Matlab to study the influence of abnormal data on relay protection. The simulation results show that the abnormal data can make distance protection extend the fault's influence and make over current protection start by error.
\end{abstract}

\section{Keywords}

Relay Protection, Abnormal Data, Fourier Algorithm

\section{Introduction}

With the fast development of information technology, communication technology and computer technology, the smart substation has been developed rapidly. The signal collecting facilities in the smart substation are mainly consisted of electronic instrument transformers and merging units. However, because the production technology is not very mature, the use of electronic instrument transformers brings some problems. The abnormal data is one of the most serious problems. It is the data which is usually much larger than the actual value. There are many accident reports due to abnormal data. How to decrease the influence of abnormal data is a very important research direction as discussed in [1] [2]. [3] and [4] give some methods on how to detect the abnormal data, but the influence of abnormal data is lacked. After deeply studying the abnormal data properties and smart substation's characters, this paper defines five parameters to describe the abnormal data's influence. The influence on Fourier Algorithm and relay protection are then studied. 


\section{Abnormal Data's Characters and Influence}

\subsection{Abnormal Data's Characters}

The influence of the abnormal data (Figure 1 and Figure 2) can be described by five parameters: uniformity degree, phase, error value, alternative degree and duration time. Limited by the thesis' length, the analysis process is omitted. The conclusion is as following.

1) Uniformity degree describes the difference of the gap between two adjacent abnormal data. The higher the uniformity degree is, the more the abnormal data influences the relay protection system.

Uniformity degree $=\frac{\text { The biggest distance between two abnormal points }}{\text { The smallest distance between two abnormal points }}$

2) Phase describes the phase of the abnormal data, also its position. If the abnormal data occurs in the peak value of the signal, it has the maximum influence; if it occurs in the zero crossing point, it has the minimum influence. In other positions, the influence is in the middle.

3) Error value describes the difference between the abnormal value and the normal value. The bigger the error value is, the bigger the influence is.

4) Alternative degree is defined as the angle difference of a pair of adjacent abnormal data whose values are in different sign. The bigger the alternative degree is, the smaller the influence is.
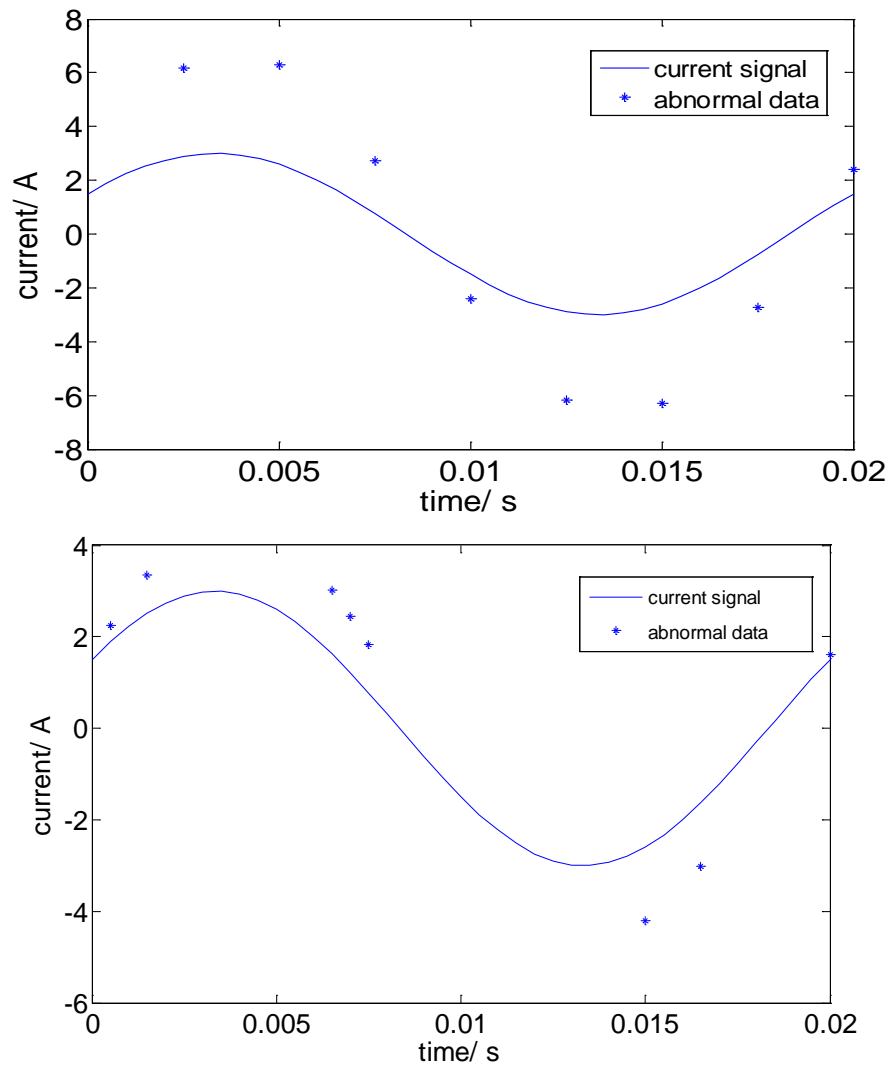

Figure 1. Abnormal data with high uniformity degree (left) and low uniformity (right). 

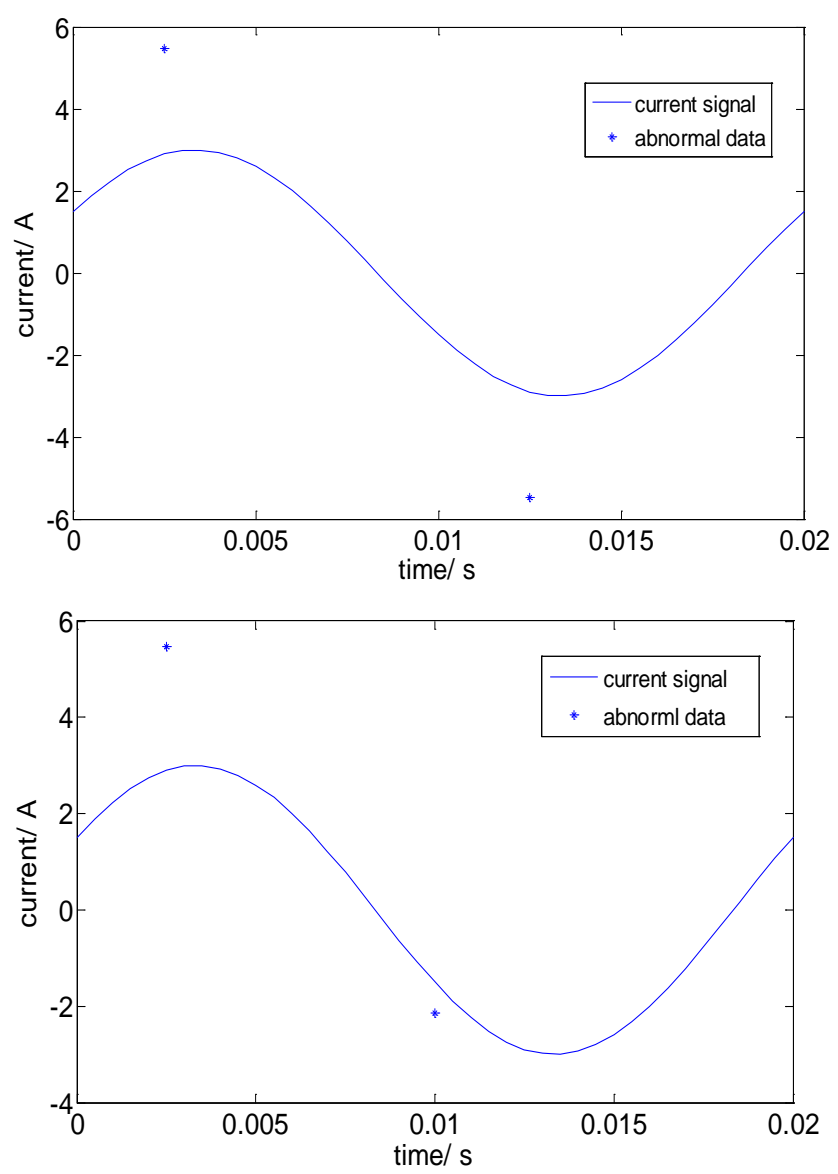

Figure 2. Abnormal data with high alternativity degree (left) and low alternativity (right).

5) Duration time describes how long time the abnormal data lasts. The longer the duration time, the bigger the influence is.

\subsection{The Influence of Abnormal Data to Fourier Algorithm}

Fourier algorithm is widely used in the relay protection, for it has the advantage of high speed, simple to realize, highly reliable and it can separate the different frequency components. The abnormal data has much influence on Fourier Algorithm.

Imagine that for the sinuous signal, there are $N$ sampling points in each period and the amplitude of the sinuous signal equals to $A$. The distance of the abnormal data to the peak value is equal to $M$ as shown in Figure 3.

$x_{N}[i]$ is the $i^{\text {th }}$ sampling value of the sinuous signal, the abnormal data occurs in the $n^{\text {th }}$ point and its value equals to $x_{N}^{\prime}[n]$.

The expression of the original fundamental wave amplitude is,

$$
\begin{aligned}
A_{N}[1] & =\sum_{i=0}^{N-1} x_{N}[i] e^{-j \frac{2 \pi}{N} *_{i}} \\
& =\sum_{i=0}^{n-1} x_{N}[i] e^{-j \frac{2 \pi}{N} *_{i}}+x_{N}[n] e^{-j \frac{2 \pi}{N} *_{n}}+\sum_{i=n+1}^{N-1} x_{N}[i] e^{-j \frac{2 \pi}{N} *_{i}}
\end{aligned}
$$




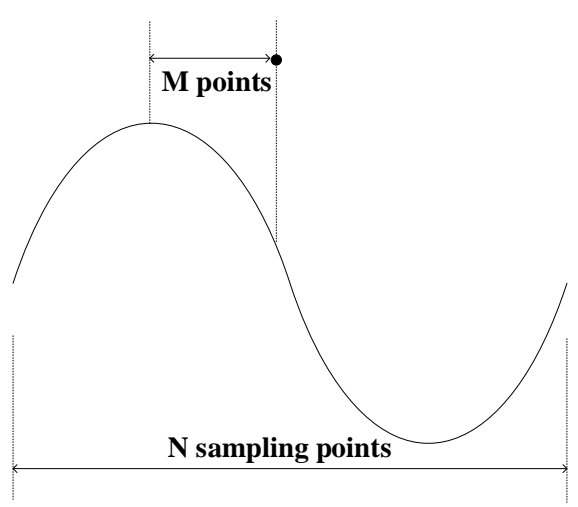

Figure 3. Abnormal data position.

The expression of fundamental wave amplitude with abnormal data is,

$$
\begin{aligned}
A_{N}^{\prime}[1] & =\sum_{i=0}^{N-1} x_{N}^{\prime}[i] e^{-j \frac{2 \pi}{N} *_{i}} \\
& =\sum_{i=0}^{n-1} x_{N}[i] e^{-j \frac{2 \pi}{N} *_{i}}+x_{N}^{\prime}[n] e^{-j \frac{2 \pi}{N} *_{n}}+\sum_{i=n+1}^{N-1} x_{N}[i] e^{-j \frac{2 \pi}{N} *_{i}}
\end{aligned}
$$

Suppose $\mathrm{x}_{N}^{\prime}[n]-\mathrm{x}_{N}[n]=s$, then we have,

$$
A_{N}^{\prime}[1]-A_{N}[1]=\left(\mathrm{x}_{N}^{\prime}[n]-\mathrm{x}_{N}[n]\right) \mathrm{e}^{-j \frac{2 \pi}{N} * \mathrm{n}}=s^{*} \mathrm{e}^{-j \frac{2 \pi}{N} * \mathrm{n}}
$$

According to Fourier Algorithm, $A_{N}[1]=\mathrm{Ae}^{j \frac{2 \pi}{N}(-\mathrm{M}-n)}$, so

$$
\begin{aligned}
A_{N}^{\prime}[1]= & A \mathrm{e}^{j \frac{2 \pi}{N}(-\mathrm{M}-n)}+s \mathrm{e}^{-j \frac{2 \pi}{N} * \mathrm{n}} \\
& =(\mathrm{s}+\mathrm{A} \cos (\theta)-\mathrm{j} \operatorname{Asin}(\theta)) \mathrm{e}^{-j \frac{2 \pi}{N} * \mathrm{n}}, \theta=\frac{2 \pi}{N} * M, \quad 0 \leq M \leq \frac{N}{2}
\end{aligned}
$$

So the error of signal amplitude with abnormal data is,

$$
\left|A_{N}^{\prime}[1]\right|-\left|A_{N}[1]\right|=\sqrt{s^{2}+2 * s^{*} A \cos (\theta)+A^{2}}-A
$$

From Equation (6), we can see that when $s$ becomes bigger and $M$ becomes smaller, the error of the signal amplitude becomes bigger. It is reasonable to conclude that the bigger the error value of the abnormal data, the closer the abnormal point close to the peak, the more an abnormal data influences the result calculated by Fourier Algorithm.

\section{The Influence of Abnormal Data to Relay Protection}

\subsection{The Influence of Abnormal Data to Distance Protection}

In order to test the influence of abnormal data to distance protection, a simulation model is established as shown in Figure 4.

In the simulation model, the length of $L_{1}$ is $20 \mathrm{~km}$, the length of $L_{2}$ is $15 \mathrm{~km}$. The current on $L_{1}$ varies from $40 \mathrm{~A}$ to $50 \mathrm{~A}$, the current on $L_{3}$ varies from $35 \mathrm{~A}$ to $40 \mathrm{~A}$. The minimum branching factor of protection on $L_{1}$ equals to 1.7.

According to the distance protection theory, the setting value of protection is calculated by Equation (7) and Equation (8). 


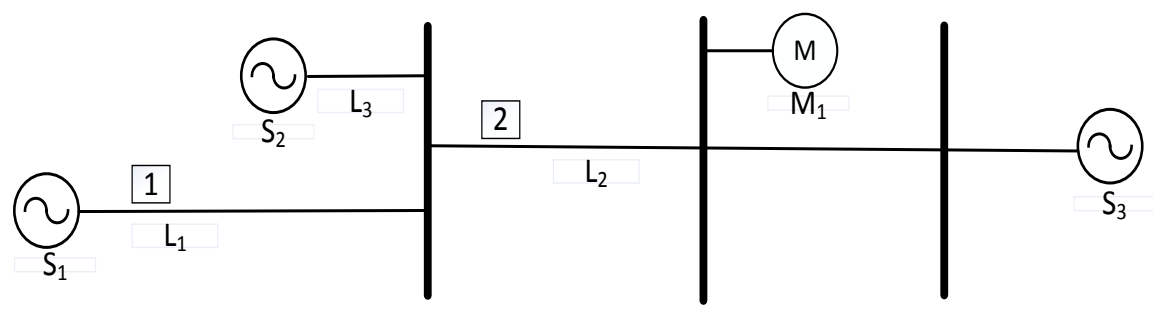

Figure 4. Model for distance protection.

$$
\begin{gathered}
Z_{\text {set1 }}^{\mathrm{I}}=K_{r e l}^{\mathrm{I}} L_{1} Z_{1} \\
Z_{\text {set } 2}^{\mathrm{I}}=K_{r e l}^{\mathrm{I}} L_{2} Z_{1} \\
Z_{\text {set } 1}^{\mathrm{II}}=K_{\text {rel }}^{\mathrm{II}}\left(L_{1}+K_{b \min } Z_{\text {set } 2}^{\mathrm{I}}\right)
\end{gathered}
$$

$Z_{1}$ is the unit length positive sequence impedance.

$K_{r e l}^{\mathrm{I}}$ is the safety factor, here we put $K_{r e l}^{\mathrm{I}}=0.8$

$K_{r e l}^{\mathrm{II}}$ is the safety factor, here we put $K_{\text {rel }}^{\mathrm{II}}=0.8$

$K_{b \min }$ is the minimum branching factor.

In the simulation, there are 40 sampled values in each period. The amplitude of the abnormal data varies from two times the original value to five times the original value. The occurrence possibility of abnormal data on voltage signal is 0.1. The simulation result is shown in Table 1.

The theoretical boundary of protection I is $16 \mathrm{~km}$. We can find that when the fault position is very close to $S_{1}$, protection I can always start normally. But when the fault position is far from $S_{1}$ especially close to the boundary of protection I $\left(15 \mathrm{~km}\right.$ to $\left.S_{1}\right)$, protection II may start instead of protection I. This is because when the fault is close to $S_{1}$, the calculated impedance is very small. Though the abnormal data may enlarge the calculated impedance (abnormal data on the voltage signal), it still falls in the area of protection I. But when the fault occurs close to the boundary of protection I, the calculated impedance may fall into the area of protection II with the influence of abnormal data. This extends the fault's influence.

\subsection{The Influence of Abnormal Data to Over current Protection}

In order to test the influence of abnormal data to over current protection, a simulation model is established as shown in Figure 5.

The length of Line 1 equals to $20 \mathrm{Km}$. The phase-to-phase rms voltage of $S_{1}$ is $35 \mathrm{kv}$; the phase-to-phase rms voltage of $S_{2}$ is $10 \mathrm{kv}$. The rated active power of Load 1 is $20 \mathrm{kw}$ and its inductive power factor equals to 0.8 ; the rated active power of Load 2 is $15 \mathrm{kw}$ and its inductive power factor equals to 0.6 . I and II are two busbars of the system. Protection A is installed very close to I and protection $B$ is installed very close to II.

According to the theory of over current protection, the setting values of instantaneous over current protection and time delay instantaneous over current protection are calculated by Equation (10) and Equation (11). 
Table 1. Simulation result of distance protection.

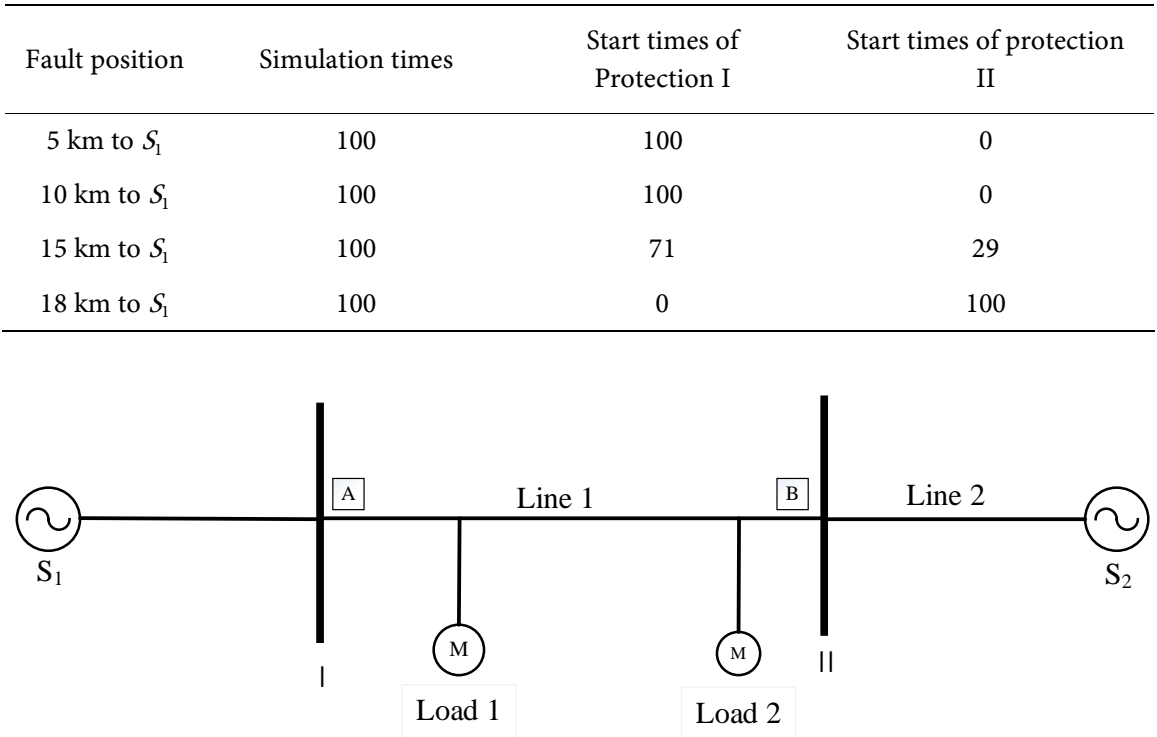

Figure 5. Model for distance protection.

$$
\begin{gathered}
I_{\text {set } 1}^{\mathrm{I}}=K_{r e l}^{\mathrm{I}} I_{k B} \\
I_{\text {set } 1}^{\mathrm{II}}=K_{r e l}^{\mathrm{II}} I_{\text {set } 2}^{\mathrm{I}}
\end{gathered}
$$

$K_{r e l}^{\mathrm{I}}$ is the safety factor of instantaneous over current protection, here we put $K_{\text {rel }}^{\mathrm{I}}=1.2$.

$K_{r e l}^{\mathrm{II}}$ is the safety factor of time delay instantaneous over current protection, here we put $K_{r e l}^{\mathrm{II}}=1.2$.

$I_{k B}$ is the minimum current when there is a fault on busbar II.

$I_{\text {set } 1}^{\mathrm{I}}$ and $I_{\text {set } 2}^{\mathrm{I}}$ are the setting values of instantaneous over current protection in Line 1 and Line 2. $I_{\text {set } 1}^{\mathrm{II}}$ is the setting value of time relay protection in Line 1.

In the simulation, there are 40 sampled values in each period. The amplitude of the ab-normal data varies from two times the original value to five times the original value. The occurrence possibility of abnormal data on current signal is 0.1 . The simulation result is shown in Table 2.

The theoretical instantaneous over current protection's boundary is $6.8 \mathrm{~km}$. We can see from the simulation result that the over current protection has the possibilities of starting without fault on the line. It is because the calculated current amplitude is enlarged with the abnormal data. This is a big threat to the safety operation of power system. We also find that in some conditions (in the last two lines) the instantaneous over current protection starts instead of time delay instantaneous over current protection. But this doesn't have much influence on the power system safety.

\section{Conclusion}

The abnormal data is a very big threat to the safety of power system. It can enlarge the amplitude calculated by Fourier Algorithm and influence the normal 
Table 2. Simulation result of over current protection of Line 1.

\begin{tabular}{cccc}
\hline Fault position & Simulation times & $\begin{array}{c}\text { Start times of } \\
\text { Protection I }\end{array}$ & $\begin{array}{c}\text { Start times of } \\
\text { protection II }\end{array}$ \\
\hline No fault & 100 & 3 & 0 \\
$3 \mathrm{~km}$ to busbar I & 100 & 100 & 0 \\
$5 \mathrm{~km}$ to busbar I & 100 & 100 & 0 \\
$10 \mathrm{~km}$ to busbar I & 100 & 2 & 98 \\
$15 \mathrm{~km}$ to busbar I & 100 & 2 & 98 \\
\hline
\end{tabular}

operation of relay protection system, extend the fault's influence. The research on new method to detect the abnormal data and avoid its influence is an urgent task for researchers.

\section{References}

[1] Li, Z.Q., Zhou, Z.X., Huang, Y.,et al. (2011) Research on Applicability of Relay Protection in Digital Substations. Power System Technology, 5, 210-215.

[2] Wang, T.W., Xie, M., Sun, Y.Q. and Shen, P.(2015) Analysis of Reliability for Relay Protection Systemin Smart Substation. Power System Protection and Control, 6, 58-66.

[3] Zhao, L., Qian, Y.C., Liu, H.J. and Li, Y.X. (2010) Abnormal Data Resisting Method in Digital Substation. Automation of Electric Power System,19, 97-99.

[4] Wu, W.J. and Zhan, J.W.(2015) A Flying Spot Detection Algorithm for Continuous Sampling Based on Removable Discontinuous Points. Power System Protection and Control, 4, 18-24.

Submit or recommend next manuscript to SCIRP and we will provide best service for you:

Accepting pre-submission inquiries through Email, Facebook, LinkedIn, Twitter, etc. A wide selection of journals (inclusive of 9 subjects, more than 200 journals)

Providing 24-hour high-quality service

User-friendly online submission system

Fair and swift peer-review system

Efficient typesetting and proofreading procedure

Display of the result of downloads and visits, as well as the number of cited articles

Maximum dissemination of your research work

Submit your manuscript at: http://papersubmission.scirp.org/

Or contact epe@scirp.org 